\title{
Fragmented pellet in the orbital apex: a dilemma to remove or not
}

\author{
Deepsekhar Das (D) , Ranjitha Gowdar Kuberappa, Sahil Agrawal (D) , \\ Sujeeth Modaboyina
}

Ophthalmology, Dr Rajendra Prasad Centre for Ophthalmic Sciences, All India Institute of Medical Sciences, New Delhi, India

\section{Correspondence to} Dr Deepsekhar Das; doc.deep.das@gmail.com

Accepted 27 June 2020

\section{DESCRIPTION}

A 21-year-old man presented to the ophthalmology casualty with sudden diminution of vision in the right eye for the past 7 days (figure 1). He gave a history of being shot by an airgun following which a pellet had entered his right eye.

On general examination, he was alert, conscious with stable vitals. On ocular examination, his best corrected visual acuity (BCVA) in the right eye was finger counting close to face and $6 / 6$ in the left eye with accurate projection of rays in both eyes. However, there was a relative afferent pupillary defect in the right side. Intraocular pressure was $15 \mathrm{~mm} \mathrm{Hg}$ in the right eye and $17 \mathrm{~mm} \mathrm{Hg}$ in the left eye. There was an ecchymosis over the lower lid skin on the right side. On slit lamp examination, in the right eye there was a localised temporal conjunctival congestion, rest of the anterior and posterior segments were within normal limits in both eyes. There was no ocular movement limitation or obvious globe displacement. X-ray of the orbit and the paranasal sinuses (anteroposterior and lateral views) revealed the presence of radiopaque multiple foreign bodies in the posterior aspect of

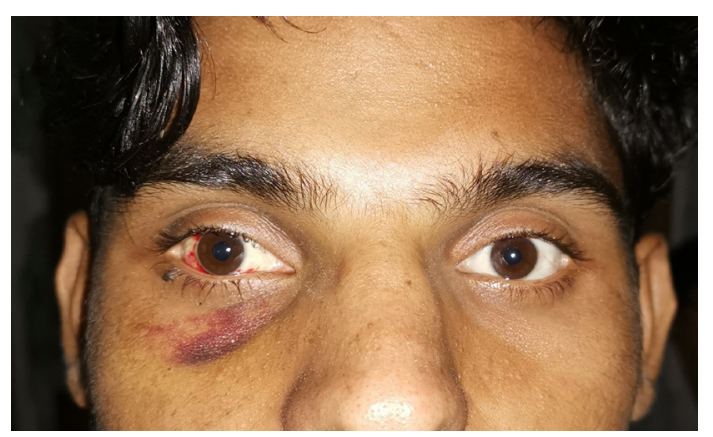

Figure 1 Clinical picture of the patient at presentation showing temporal subconjunctival haemorrhage in the right eye and ecchymosis of the lower eyelid.

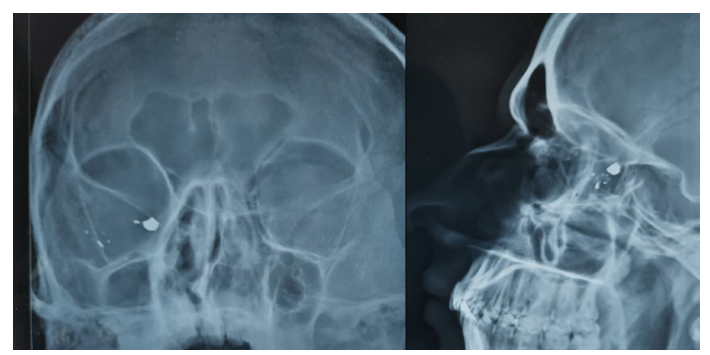

Figure 2 X-ray orbit showing fragmented multiple radio opaque foreign bodies at the orbital apex.

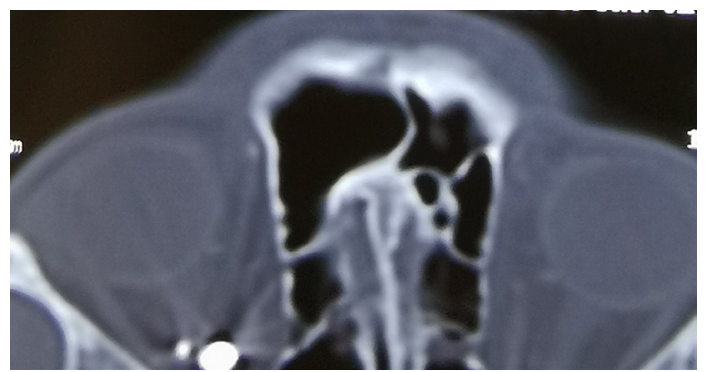

Figure 3 CT scan showing fragmented metallic hyperdense foreign bodies near the apex.

the right orbit near the apex (figure 2). A CT scan revealed features of multiple metallic foreign bodies near the apex without any obvious evidence of orbital wall fracture (figure 3 ).

The patient was diagnosed to have right eye retained intraorbital foreign bodies with traumatic optic neuropathy. The location as well as the number of foreign bodies made it difficult to plan for removal without damaging the optic nerve. On explaining the situation to the patient, he refused to undergo any form of surgery. He was treated conservatively with oral steroids (tablet prednisolone $1 \mathrm{mg} / \mathrm{kg}$, tapered gradually), the foreign bodies were left untouched. After 3 weeks, his BCVA in the right eye improved to 6/9. However, he had reduced contrast sensitivity, reduced visual field on automated perimetry and partial red-green deficiency in his right eye. The patient has been on regular follow-up ever since and there has been no change is his visual fields or contrast sensitivity at 6-month follow-up (figure 4).

Intraorbital foreign bodies are uncommon and foreign bodies in the orbital apex are rarer. Foreign bodies located at the apex are associated with significant ocular and orbital morbidity, especially if the

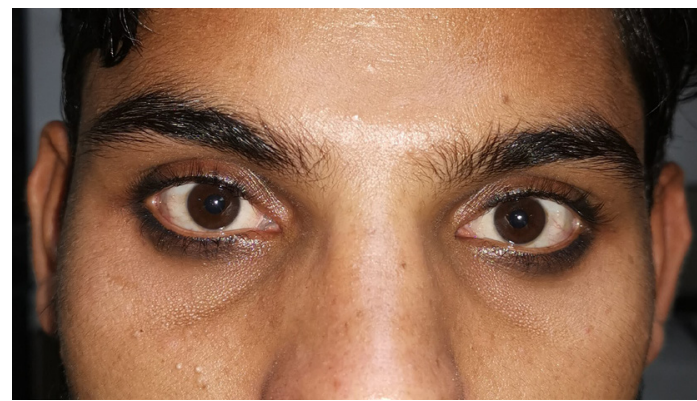

Figure 4 Clinical picture of the patient at 6-month follow-up. 
foreign body is a metallic projectile. ${ }^{12}$ Few cases may be asymptomatic initially and present after several months. ${ }^{3}$ Management of intraorbital metallic foreign body depends mainly on its size, location and composition. ${ }^{14}$ Certain metallic foreign bodies, particularly iron, copper and lead, can cause specific complications such as retinopathy, siderosis, chalcosis or systemic toxicity. ${ }^{4}$ Organic foreign bodies can cause severe inflammation and have an increased potential of subsequent infection compared with inorganic materials and warrants immediate surgical removal. ${ }^{5}$ Inorganic non-metallic foreign bodies are most commonly inert. Surgical removal of foreign bodies can be done via multiple approaches. There are few reports where foreign bodies have been successfully removed from the orbital apex using a lateral orbitotomy, endoscopic approach or a transnasal approach. ${ }^{6-8}$ However these surgeries carry a lot of risks that include failure to locate the foreign body, fragmentation at the time of removal causing collateral damage and inadvertent injury to orbital structures including the optic nerve and extraocular muscles. Keeping these factors in mind many authors advocate 'watchful waiting'

\section{Patient's perspective}

After the injury, I almost lost my vision. I did not want to lose all of it so I chose not to get operated. I feel blessed that I have regained my vision.

\section{Learning points}

- Orbital foreign bodies sitting at the apex may not be always associated with significant deprivation of visual acuity; however, there is always a possibility of developing optic neuropathy.

- All intraorbital foreign bodies may not require removal. The number of foreign bodies, their composition, nature and location are being considered. as an option for inert foreign bodies not causing significant symptoms, which was also done in our case. ${ }^{3}$

To our knowledge, fragmented foreign bodies located at the apex have never been reported before. The location and the fragmented state of the foreign body made it an impossible task to operate without causing damage to the optic nerve and other vital structures at the apex. In our case, the foreign body was inert; therefore, conservative approach was a good option and the patient had a satisfactory outcome.

Contributors DD, SA and SM participated in diagnosing and management of the patient. DD and RGK participated in the design, preparing and finalising the manuscript.

Funding The authors have not declared a specific grant for this research from any funding agency in the public, commercial or not-for-profit sectors.

Competing interests None declared.

Patient consent for publication Obtained.

Provenance and peer review Not commissioned; externally peer reviewed.

\section{ORCID iDs}

Deepsekhar Das http://orcid.org/0000-0002-4446-0274

Sahil Agrawal http://orcid.org/0000-0001-6667-249X

\section{REFERENCES}

1 Finkelstein M, Legmann A, Rubin PA. Projectile metallic foreign bodies in the orbit: a retrospective study of epidemiologic factors, management, and outcomes. Ophthalmology 1997;104:96-103.

2 Tian Y-M, Gao X-W, Ren B, et al. Clinical observation on removal of small foreign bodies touching the optic nerve in the deep orbital region: a case series. Orbit 2014:33:210-3.

3 Nasr AM, Haik BG, Fleming JC, et al. Penetrating orbital injury with organic foreign bodies. Ophthalmology 1999;106:523-32.

$4 \mathrm{Ho}$ VH, Wilson MW, Fleming JC, et al. Retained intraorbital metallic foreign bodies. Ophthal Plast Reconstr Surg 2004;20:232-6.

5 Fulcher TP, McNab AA, Sullivan TJ. Clinical features and management of intraorbital foreign bodies. Ophthalmology 2002;109:494-500.

6 Wu W, SY L, Liu CY, et al. Image-Guided endoscopic combined with deep lateral orbitotomy removal of a small foreign body at the deep lateral orbital apex. J Craniofac Surg 2014;25:1547-9.

$7 \mathrm{Koo} \mathrm{Ng} \mathrm{NKF}$, Jaberoo MC, Pulido M, et al. Image guidance removal of a foreign body in the orbital apex. Orbit 2009:28:404-7.

8 Levin B, Goh ES, Ng YH, et al. Endoscopic removal of a foreign body in the orbital apex abutting the optic nerve. Singapore Med J 2019;60:265-6.

Copyright 2020 BMJ Publishing Group. All rights reserved. For permission to reuse any of this content visit https://www.bmj.com/company/products-services/rights-and-licensing/permissions/

BMJ Case Report Fellows may re-use this article for personal use and teaching without any further permission.

Become a Fellow of BMJ Case Reports today and you can:

- Submit as many cases as you like

- Enjoy fast sympathetic peer review and rapid publication of accepted articles

- Access all the published articles

- Re-use any of the published material for personal use and teaching without further permission

Customer Service

If you have any further queries about your subscription, please contact our customer services team on +44 (0) 2071111105 or via email at support@bmj.com.

Visit casereports.bmj.com for more articles like this and to become a Fellow 